\title{
Fused Nonacyclic Electron Acceptors for Efficient Polymer Solar Cells
}

\author{
Shuixing Dai, ${ }^{\dagger, \ddagger}$ Fuwen Zhao ${ }^{\S}$ Qianqian Zhang, $\|$ Tsz-Ki Lau, ${ }^{\perp}$ Tengfei Li, ${ }^{\dagger}$ Kuan Liu, ${ }^{\dagger}$ Qidan Ling, \\ Chunru Wang, ${ }^{\S}$ Xinhui Lu, ${ }^{\perp}$ Wei You, ${ }^{\|}$and Xiaowei Zhan*, ${ }^{\dagger}$ \\ ${ }^{\dagger}$ Department of Materials Science and Engineering, College of Engineering, Key Laboratory of Polymer Chemistry and Physics of \\ Ministry of Education, Peking University, Beijing 100871, China \\ ${ }^{\ddagger}$ Fujian Key Laboratory of Polymer Materials, College of Materials Science and Engineering, Fujian Normal University, Fuzhou \\ 350007, China \\ ${ }^{\S}$ Institute of Chemistry, Chinese Academy of Sciences, Beijing 100190, China \\ "Department of Chemistry, University of North Carolina at Chapel Hill, Chapel Hill, North Carolina 27599-3290, United States \\ ${ }^{\perp}$ Department of Physics, Chinese University of Hong Kong, New Territories, Hong Kong, China
}

\section{Supporting Information}

ABSTRACT: We design and synthesize four fused-ring electron acceptors based on 6,6,12,12-tetrakis(4-hexylphenyl)-indacenobis(dithieno $\left[3,2-b ; 2^{\prime}, 3^{\prime}-d\right]$ thiophene) as the electron-rich unit and 1,1-dicyanomethylene-3-indanones with 02 fluorine substituents as the electron-deficient units. These four molecules exhibit broad (550-850 nm) and strong absorption with high extinction coefficients of $(2.1-2.5) \times 10^{5}$ $\mathrm{M}^{-1} \mathrm{~cm}^{-1}$. Fluorine substitution downshifts the LUMO energy level, red-shifts the absorption spectrum, and enhances electron mobility. The polymer solar cells based on the fluorinated electron acceptors exhibit power conversion efficiencies as high as $11.5 \%$, much higher than that of their nonfluorinated counterpart $(7.7 \%)$. We investigate the effects of the fluorine atom number and position on electronic properties, charge transport, film morphology, and photovoltaic properties.

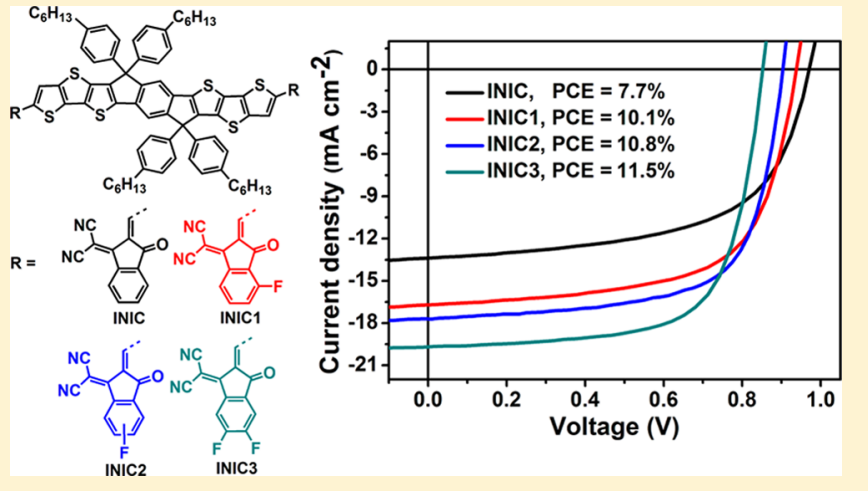

\section{INTRODUCTION}

Organic solar cells (OSCs) are considered to be one of the promising alternatives to silicon-based solar cells since they present unique features, such as low processing cost, semitransparency, flexibility, and light weight. ${ }^{1-3}$ For a long period of time, OSCs mainly employed fullerene derivatives (e.g., $\mathrm{PC}_{61} \mathrm{BM}$ and $\left.\mathrm{PC}_{71} \mathrm{BM}\right)$ as electron acceptors which, paired with electron donating polymers or small molecules, have successfully achieved power conversion efficiencies (PCEs) over $11 \%{ }^{4-7}$ However, fullerene derivatives suffer from several shortcomings, such as poor absorption in the visible region, limited tunability of energy levels, and morphology instability, which hinder the further development of OSCs. On the other hand, nonfullerene electron acceptors possess advantages over their fullerene counterpart, such as enhanced absorption in the visible and even near-infrared (NIR) region, tunable energy levels, good device stability, and easy synthesis and purification. For all these reasons, rapid progress has been made with these nonfullerene electron acceptors, which have led to impressive PCEs. ${ }^{8-35}$

Recently, indacenodithiophene (IDT) - and indacenodithieno[3,2-b] thiophene (IDTT)-based fused-ring electron acceptors (FREAs) have attracted considerable attention. $^{36-51}$ These FREAs exhibit broad and strong absorption, suitable lowest unoccupied molecular orbital (LUMO) and highest occupied molecular orbital (HOMO) energy levels, and high electron mobility. OSCs based on these FREAs have exhibited high PCEs with small energy loss ${ }^{51}$ and good device stability. ${ }^{37}$ Most of these FREAs, such as ITIC, ${ }^{36}$ ITIC-Th, ${ }^{37}$ and IDIC, ${ }^{38,48}$ are based on IDT or IDTT donor unit and 1,1-dicyanomethylene-3-indanone (IC) acceptor unit.

In this work, we design and synthesize an electron-rich unit 6,6,12,12-tetrakis(4-hexylphenyl)- indacenobis(dithieno[3,2$\left.b ; 2^{\prime}, 3^{\prime}-d\right]$ thiophene) (IBDT) and three electron-deficient units fluorinated IC, to construct a small library of four FREAs (INIC series) based on IBDT end-capped with IC or fluorinated IC (Chart 1, Scheme 1). Our molecular design rationale is as follows. First, IBDT has larger rigid and coplanar structure and stronger electron-donating ability than IDT and IDTT, both of which are beneficial to enhancing the absorption and charge transport. Second, fluorinated IC has stronger electron-withdrawing ability than IC due to strong electronegativity of fluorine atom, and promotes intermolecular

Received: December 12, 2016

Published: January 6, 2017 
Chart 1. Chemical Structures of INIC Series and FTAZ
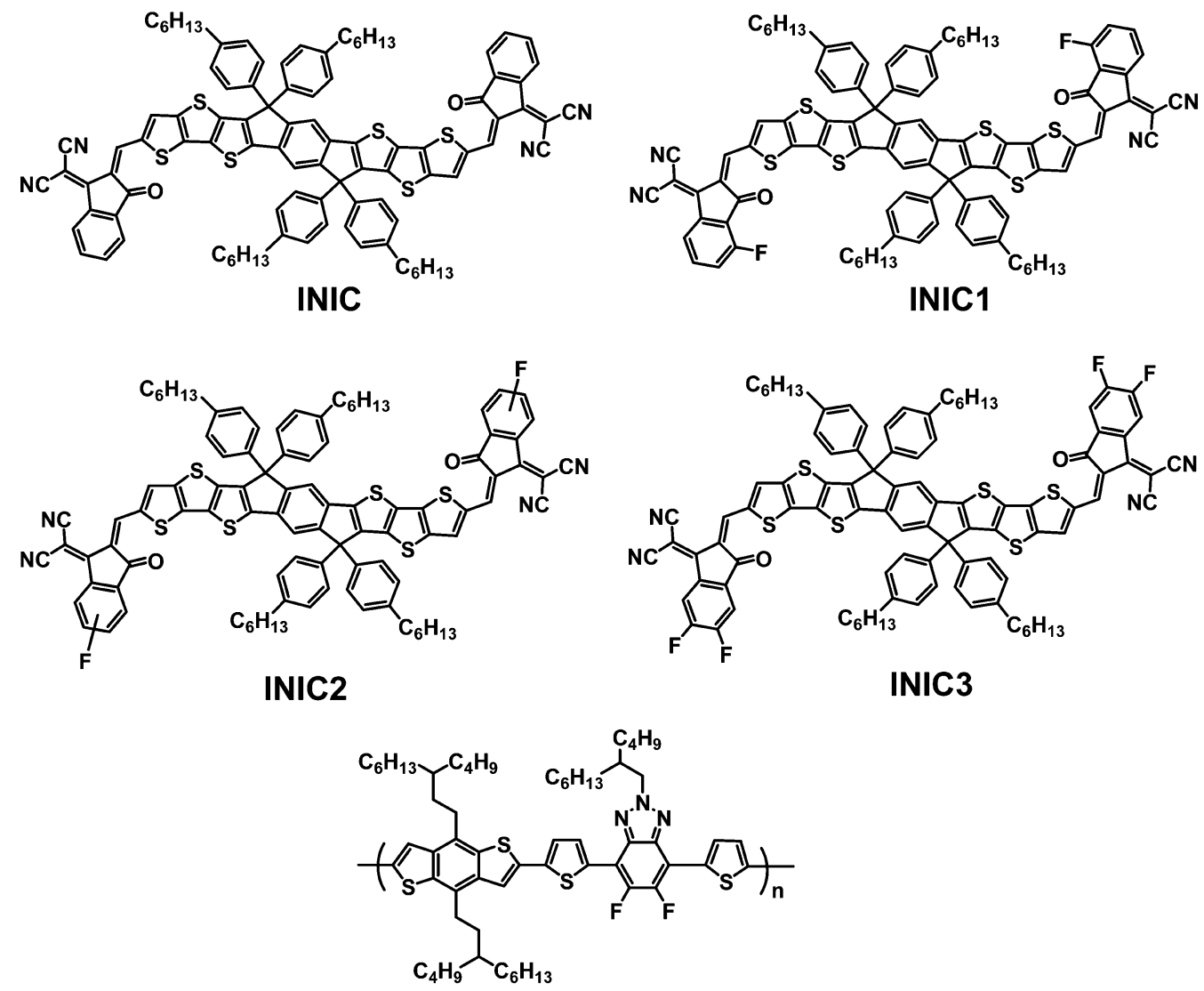

FTAZ

interactions through forming noncovalent $\mathrm{F}-\mathrm{S}$ and $\mathrm{F}-\mathrm{H}$ bonds, which is favorable for charge transport. ${ }^{52-54}$ Third, "acceptor-donor-acceptor" structure in INIC series can induce intramolecular charge transfer and lead to broad and strong absorption throughout the visible and even NIR region $(500-850 \mathrm{~nm})$. Indeed, our results show that fluorinated INIC exhibit lower energy levels, red-shifted absorption, and higher electron mobility than nonfluorinated INIC. Furthermore, nonfullerene OSCs based on fluorinated INIC electron acceptor and a wide-band-gap polymer donor FTAZ ${ }^{55}$ (Chart 1) exhibit PCEs as high as $11.5 \%$, significantly higher than that of nonfluorinated INIC (7.7\%). More importantly, with this series, we are able to investigate the effects of the number of fluorine atoms and their positions on electronic properties, charge transport, film morphology, and photovoltaic properties.

\section{RESULTS AND DISCUSSION}

Synthesis and Characterization. The fluorinated IC moieties (2, 4, and 7) were synthesized from corresponding monofluorinated or difluorinated indanedione $(1,3$, and 6$)$ and malononitrile (Scheme 1). Compound 4 is a mixture of two isomers, which was difficult to separate. Thus, we used them together for the final condensation reaction without separation. Stille coupling reaction between compounds 8 and 9 with $\mathrm{Pd}\left(\mathrm{PPh}_{3}\right)_{4}$ catalyst yielded compound 10. A double nucleophilic addition of (4-hexylphenyl)magnesium bromide to the ester groups in 10, followed by intramolecular cyclization via acid-mediated Friedel-Crafts reaction afforded IBDT (11). Compound 11 was lithiated by $n$-butyllithium in THF solution at $-78{ }^{\circ} \mathrm{C}$, then quenched by dry DMF to afford aldehyde $\mathbf{1 2}$.
INIC, INIC1, INIC2 and INIC3 were synthesized using Knoevenagel condensation reactions between IC, 2, 4, 7 and aldehyde 12, respectively. The new compounds were fully characterized by spectroscopic methods and elemental analysis (see the Supporting Information).

The four INIC series compounds exhibit good solubility in organic solvents, such as chloroform (CF) and o-dichlorobenzene (DCB). The thermal stability of these four molecules was investigated using thermogravimetric analysis (TGA) (Figure S1, Supporting Information). The TGA curves of four compounds show decomposition temperatures $\left(T_{\mathrm{d}}, 5 \%\right.$ weight loss) varying from 302 to $342{ }^{\circ} \mathrm{C}$, which indicate good thermal stability.

The UV-vis absorption spectra of INIC, INIC1, INIC2, and INIC3 were measured in chloroform solution and thin films. In solution, four molecules show similar absorption spectra shapes with peaks from 692 to $710 \mathrm{~nm}$ (Figure 1a), and similar molar extinction coefficients from $2.1 \times 10^{5}$ to $2.5 \times 10^{5} \mathrm{M}^{-1} \mathrm{~cm}^{-1}$ at maximum absorption peaks (Table 1 ). In thin films, all four molecules show red-shifted and broader absorption spectra than their solutions. The absorption peaks of these four compounds red shift gradually from 706 to $744 \mathrm{~nm}$ (Figure 1b). Fluorination red-shifts the absorption of INIC: INIC2 with $\mathrm{F}$ at meta-position exhibits red-shifted absorption relative to INIC1 with F at ortho-position, and INIC3 with two F atoms exhibits red-shifted absorption relative to INIC1 and INIC2 with one $\mathrm{F}$ atom. The optical band gaps of INIC, INIC1, INIC2, and INIC3 are calculated to be $1.57,1.56,1.52$, and $1.48 \mathrm{eV}$ from the absorption edge, respectively (Table 1 ). 
Scheme 1. Synthetic Routes for INIC, INIC1, INIC2, and INIC3

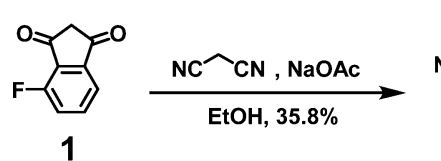<smiles>N#Cc1ccccc1C(=O)O</smiles>
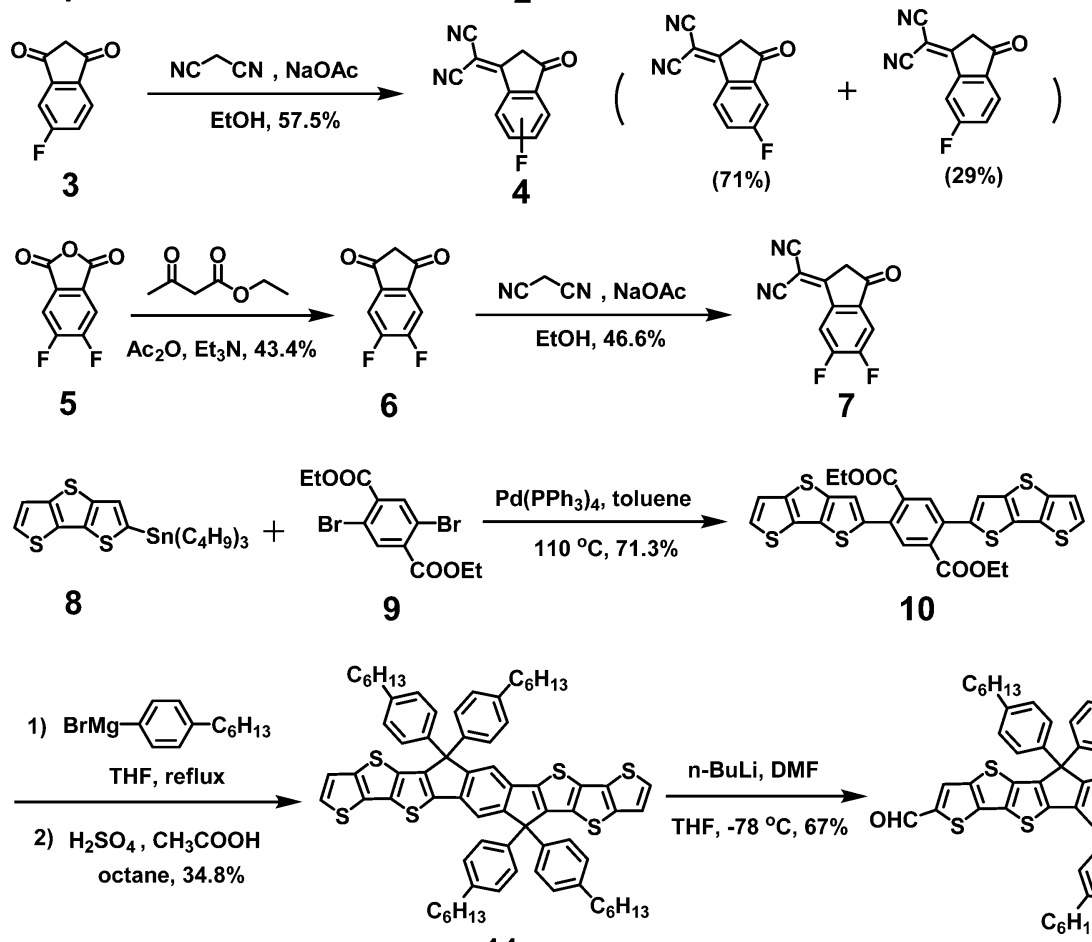

11

10

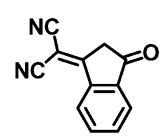

INIC $74.6 \%$

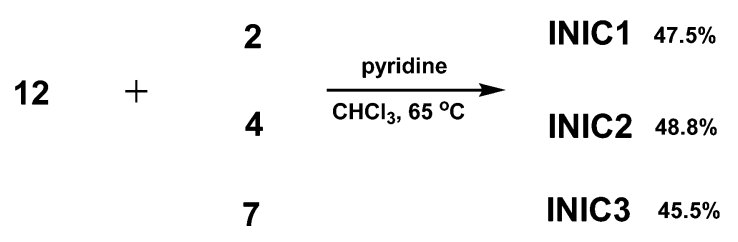

Cyclic voltammetry (CV) was employed to investigate the electrochemical properties of INIC, INIC1, INIC2, and INIC3 (Figure 1c). Four compounds exhibit irreversible reduction waves and quasi-reversible oxidation waves. The HOMO and LUMO energy levels are calculated from the onset oxidation and reduction potentials, assuming the absolute energy level of $\mathrm{FeCp}_{2}{ }^{+/ 0}$ to be $4.8 \mathrm{eV}$ below vacuum. The HOMO levels of INIC, INIC1, INIC2 and INIC3 are estimated to be $-5.45 \mathrm{eV}$ to $-5.54 \mathrm{eV}$ and LUMO levels are $-3.88 \mathrm{eV}$ to $-4.02 \mathrm{eV}$ (Figure 1d, Table 1). The fluorination downshifts the molecular HOMO and LUMO levels. Specifically, INIC3 with two fluorines has lower LUMO level than INIC1 and INIC2 with one fluorine, whereas three fluorine-modified molecules show similar HOMO levels. The band gaps of INIC, INIC1, INIC2, and INIC3 estimated from the CV data are 1.57, 1.57, 1.54, and $1.50 \mathrm{eV}$, respectively, similar to the optical band gaps.

The electron mobilities of four compounds were measured using the space charge-limited current (SCLC) method (Figure S2). The electron mobilities of INIC, INIC1, INIC2 and INIC3 are $6.1 \times 10^{-5}, 1.0 \times 10^{-4}, 1.2 \times 10^{-4}$, and $1.7 \times 10^{-4} \mathrm{~cm}^{2} \mathrm{~V}^{-1}$ $\mathrm{s}^{-1}$, respectively (Table $\mathrm{S} 1$ ). Fluorinated compounds, particularly difluorinated INIC3, exhibit higher mobility.

Photovoltaic Properties. Our previously reported wideband-gap $(2.00 \mathrm{eV})$ polymer donor FTAZ exhibits strong absorption at $400-620 \mathrm{~nm}$ with a molar extinction coefficient of $9.8 \times 10^{4} \mathrm{M}^{-1} \mathrm{~cm}^{-1}$, which is complementary with absorption of INIC series (Figure S3). ${ }^{55}$ The energy levels of FTAZ (HOMO $=-5.38 \mathrm{eV}$; LUMO $=-3.17 \mathrm{eV}$ ) match with those of INIC series (Figure 1d). FTAZ exhibits a high hole mobility of $1.2 \times 10^{-3} \mathrm{~cm}^{2} \mathrm{~V}^{-1} \mathrm{~s}^{-1}$, 6 matching with those of INIC series (Table S1). Thus, we used FTAZ as a donor and INIC series as acceptors to fabricate bulk heterojunction $(\mathrm{BHJ})$ OSCs with a structure of indium tin oxide (ITO) $/ \mathrm{ZnO} /$ FTAZ:acceptor $/ \mathrm{MoO}_{x} / \mathrm{Ag}$. The optimized FTAZ/acceptor weight ratio is $1: 1.5$ (Table S2). The optimized 1,8diiodooctane (DIO) content is $0.25 \%$ DIO (v/v) (Table S3). Table 2 summarizes the open circuit voltage $\left(V_{\mathrm{OC}}\right)$, short circuit current density $\left(J_{\mathrm{SC}}\right)$, fill factor $(\mathrm{FF})$, and PCE of the optimized devices. The current density-voltage $(J-V)$ curves of the best PSCs are shown in Figure 2a. 

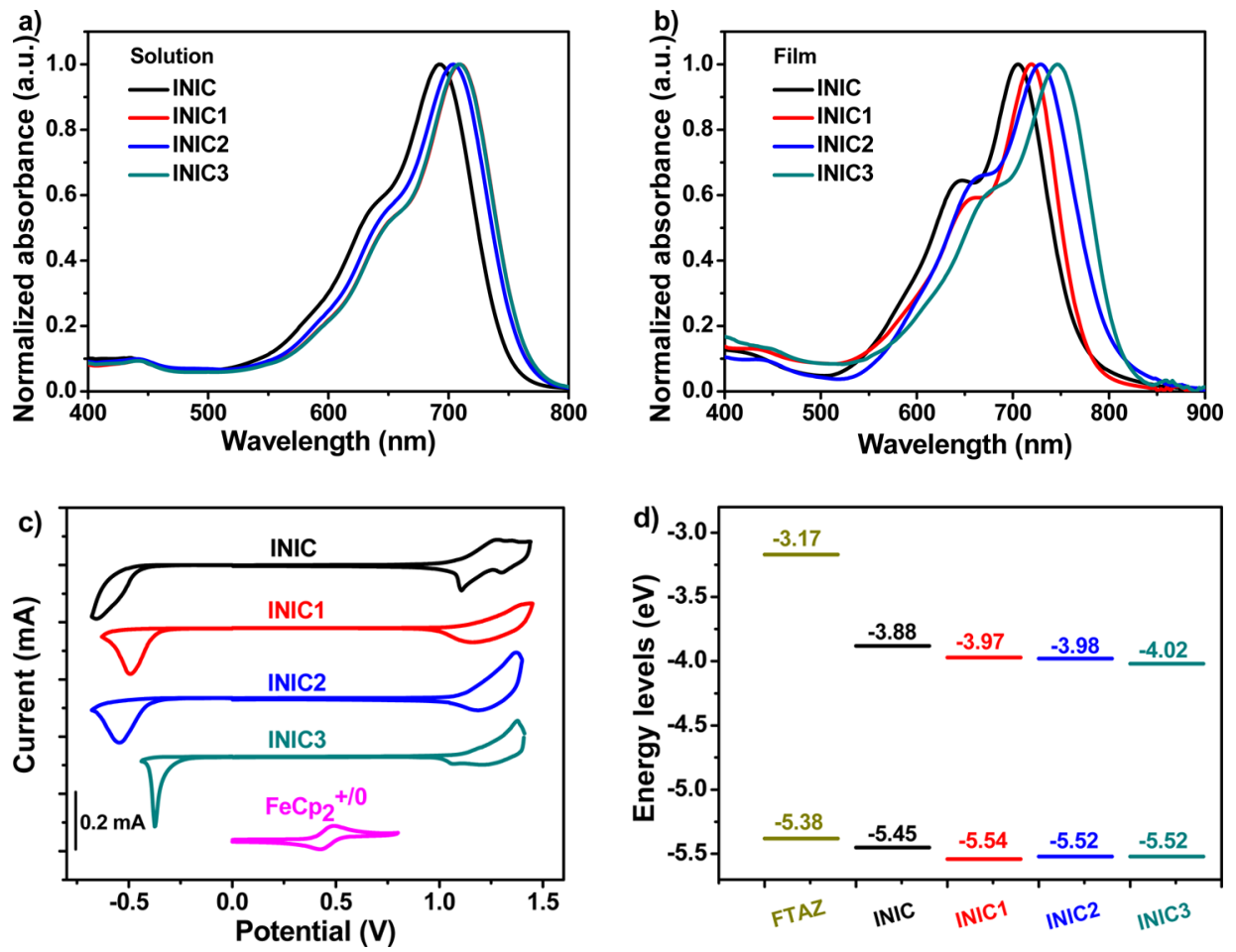

Figure 1. (a) UV-vis absorption spectra of INIC, INIC1, INIC2, and INIC3 in chloroform and (b) as a thin film; (c) cyclic voltammograms for INIC, INIC1, INIC2, and INIC3; and (d) energy levels for FTAZ, INIC, INIC1, INIC2, and INIC3.

Table 1. Absorption and Energy Levels of INIC, INIC1, INIC2, and INIC3

\begin{tabular}{|c|c|c|c|c|c|c|c|c|}
\hline compd & $T_{\mathrm{d}}\left({ }^{\circ} \mathrm{C}\right)^{a}$ & $\lambda_{\mathrm{s}, \max }(\mathrm{nm})^{b}$ & $\lambda_{\mathrm{f}, \max }(\mathrm{nm})^{c}$ & $\varepsilon_{\max }\left(\mathrm{M}^{-1} \mathrm{~cm}^{-1}\right)^{d}$ & $E_{\mathrm{g}}^{\text {opt }}(\mathrm{eV})^{e}$ & HOMO $(\mathrm{eV})^{f}$ & LUMO $(\mathrm{eV})^{g}$ & $E_{\mathrm{g}}^{\mathrm{cv}}(\mathrm{eV})^{h}$ \\
\hline INIC & 311 & 692 & 706 & $2.1 \times 10^{5}$ & 1.57 & -5.45 & -3.88 & 1.57 \\
\hline INIC1 & 302 & 710 & 720 & $2.2 \times 10^{5}$ & 1.56 & -5.54 & -3.97 & 1.57 \\
\hline INIC2 & 342 & 704 & 728 & $2.1 \times 10^{5}$ & 1.52 & -5.52 & -3.98 & 1.54 \\
\hline INIC3 & 327 & 710 & 744 & $2.5 \times 10^{5}$ & 1.48 & -5.52 & -4.02 & 1.50 \\
\hline
\end{tabular}

${ }^{a}$ Decomposition temperature measured from TGA. ${ }^{b}$ Absorption maximum in solution. ${ }^{c}$ Absorption maximum in film. ${ }^{d}$ Molar extinction coefficient at $\lambda_{\max }$ in solution. ${ }^{e}$ Optical band gap calculated from the absorption edge of thin film. ${ }^{f_{\mathrm{HOMO}}}$ energy level estimated from the onset oxidation potential. ${ }^{g}$ LUMO energy level estimated from the onset reduction potential. ${ }^{h}$ HOMO-LUMO gap estimated from CV.

Table 2. Performance of the Optimized OSCs Based on FTAZ/Acceptor

\begin{tabular}{|c|c|c|c|c|c|c|c|}
\hline \multirow[b]{2}{*}{ device $^{a}$} & \multirow[b]{2}{*}{$V_{\mathrm{OC}}(\mathrm{V})$} & \multirow[b]{2}{*}{$J_{S C}\left(\mathrm{~mA} \mathrm{~cm}^{-2}\right)$} & \multirow[b]{2}{*}{ FF (\%) } & \multicolumn{2}{|c|}{ PCE (\%) } & \multirow[b]{2}{*}{ calculated $J_{\mathrm{SC}}\left(\mathrm{mA} \mathrm{cm}^{-2}\right)$} & \multirow[b]{2}{*}{$E_{\text {loss }}(\mathrm{eV})$} \\
\hline & & & & best & $\mathrm{avg}^{b}$ & & \\
\hline FTAZ/INIC & $0.957 \pm 0.006$ & $13.51 \pm 0.18$ & $57.9 \pm 1.3$ & 7.7 & 7.5 & 13.00 & 0.61 \\
\hline FTAZ/INIC1 & $0.929 \pm 0.003$ & $16.63 \pm 0.06$ & $64.3 \pm 0.4$ & 10.1 & 9.9 & 15.93 & 0.63 \\
\hline FTAZ/INIC2 & $0.903 \pm 0.004$ & $17.56 \pm 0.20$ & $66.8 \pm 0.9$ & 10.8 & 10.6 & 17.17 & 0.62 \\
\hline FTAZ/INIC3 & $0.857 \pm 0.003$ & $19.44 \pm 0.24$ & $67.4 \pm 1.0$ & 11.5 & 11.2 & 19.13 & 0.62 \\
\hline
\end{tabular}

Fluorination of INIC decreases average $V_{\mathrm{OC}}$ of OSCs from 0.957 to $0.857 \mathrm{~V}$, which is consistent with the trend of lowering LUMO by fluorination in INIC series. The OSCs based on nonfluorinated INIC show average $J_{\mathrm{SC}}$ value of $13.51 \mathrm{~mA} \mathrm{~cm}^{-2}$, while fluorination of INIC enhances average $J_{S C}$ to $16.63-19.44$ $\mathrm{mA} \mathrm{cm}^{-2}$. In particular, the OSCs based on difluorinated INIC3 show the highest $J_{\mathrm{SC}}$ of $19.68 \mathrm{~mA} \mathrm{~cm}{ }^{-2}$. The trend in fill factor (FF) is similar to that in $J_{\mathrm{SC}}$. The OSCs based on nonfluorinated INIC show average FF value of $57.9 \%$, while fluorination of INIC enhances average FF to $64.3 \%-67.4 \%$. In particular, the OSCs based on difluorinated INIC3 show the highest FF of $68.5 \%$. The best PCE of the OSCs based on nonfluorinated INIC is $7.7 \%$, while the best PCE of the OSCs based on monofluorinated INIC1 and INIC2 is $10.1 \%$ and $10.8 \%$, respectively. The OSCs based on difluorinated INIC3 show the best performance: $V_{\mathrm{OC}}$ of $0.852 \mathrm{~V}, J_{\mathrm{SC}}$ of $19.68 \mathrm{~mA}$ $\mathrm{cm}^{-2}$, FF of $68.5 \%$, and PCE of $11.5 \%$. Clearly, fluorination of INIC significantly enhances the performance of nonfullerene OSCs. The photon energy loss $\left(E_{\text {loss }}\right)$ is calculated using the formula $E_{\text {loss }}=E_{\mathrm{g}}-\mathrm{e} V_{\mathrm{OC}}{ }^{57,58}$ The $E_{\text {loss }}$ values of the OSCs are $0.61-0.63 \mathrm{eV}$, which are relatively small.

The external quantum efficiency (EQE) spectra of the optimized devices are shown in Figure 2b. The OSCs based on these four INIC acceptors show broad photoresponse extending from 300 to $850 \mathrm{~nm}$. The maximum EQE values of INIC, INIC1, INIC2 and INIC3-based devices are 62.6\%, 

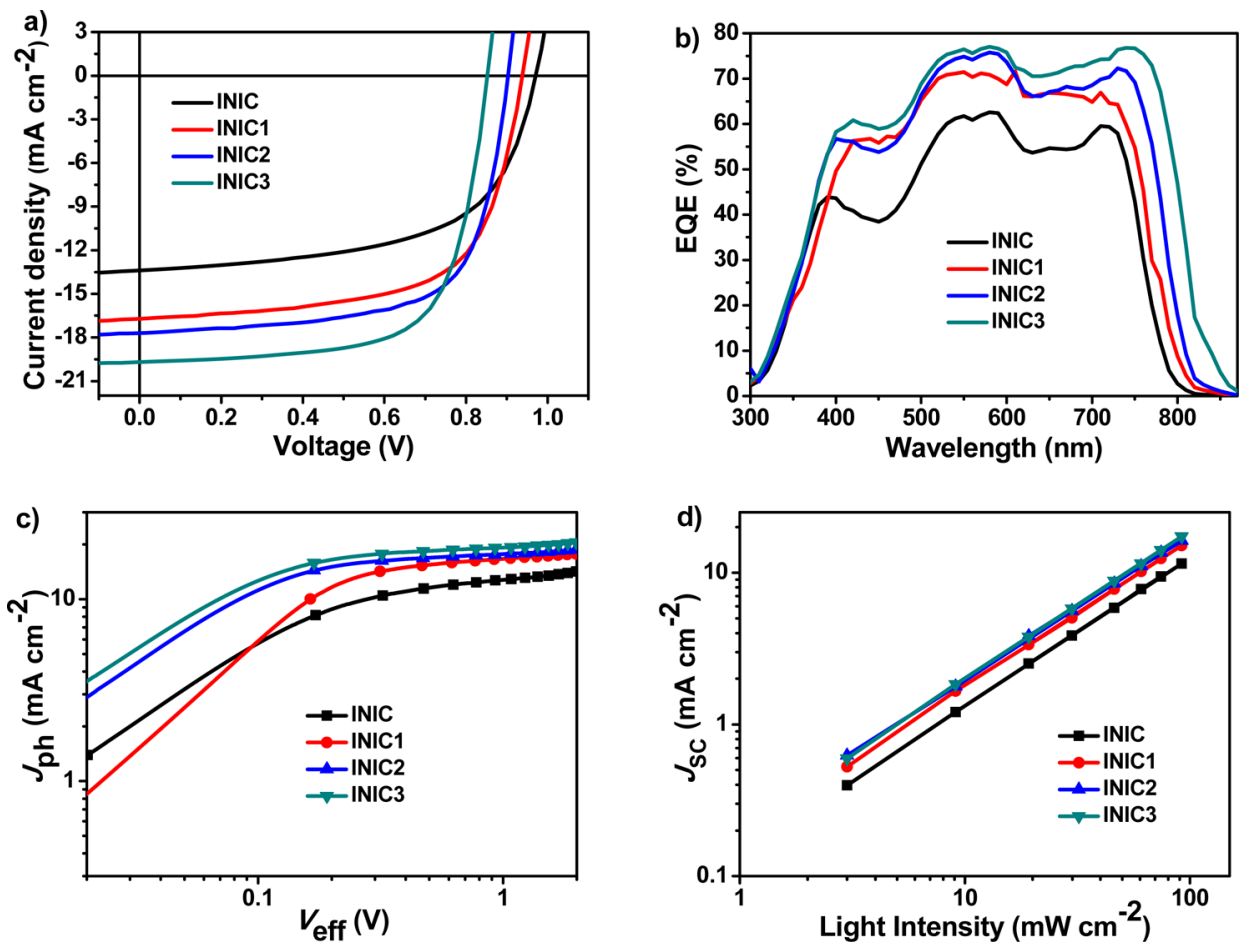

Figure 2. (a) $J-V$ characteristics and (b) EQE spectra of the best OSCs under illumination of an AM $1.5 \mathrm{G}$ at $100 \mathrm{~mW} \mathrm{~cm}^{-2}$; (c) $J_{\mathrm{ph}}$ versus $V_{\text {eff }}$ characteristics; and (d) $J_{S C}$ versus light intensity of the optimized devices.

$71.5 \%, 75.8$ and $77.0 \%$, respectively, indicating efficient charge generation and collection. In the NIR region, the IPCE spectra are broadened and enhanced gradually from INIC to INIC1, INIC2 and INIC3, resembling the absorption profile of the four INIC acceptors in the NIR region (Figure $1 \mathrm{~b}$ ). The $J_{S C}$ values of INIC, INIC1, INIC2 and INIC3-based devices calculated from integration of the EQE spectra with the AM 1.5G reference spectrum are $13.00,15.93,17.17$, and $19.13 \mathrm{~mA} \mathrm{~cm}^{-2}$, respectively, which are in good agreement with $J_{\mathrm{SC}}$ values measured from $J-V$ (the error is $<5 \%$, Table 2 ).

To probe the exciton/charge dynamics, we measured the photocurrent density $\left(J_{\text {ph }}\right)$ versus the effective voltage $\left(V_{\text {eff }}\right)$ to study the charge generation, dissociation and extraction properties. $J_{\mathrm{ph}}$ is defined as $J_{\mathrm{L}}-J_{\mathrm{D}}$, where $J_{\mathrm{L}}$ and $J_{\mathrm{D}}$ are the photocurrent densities under illumination and in the dark, respectively. $V_{\text {eff }}$ is defined as $V_{0}-V_{\text {bias }}$, where $V_{0}$ is the voltage at which photocurrent is zero and $V_{\text {bias }}$ is the applied voltage bias. In Figure $2 c, J_{\mathrm{ph}}$ reaches saturation $\left(J_{\text {sat }}\right)$ at $2 \mathrm{~V}$, suggesting the charge recombination reach the minimal level and all the charge are collected by the electrodes. The charge dissociation probability $(P(E, T))$ can be calculated from $J_{\mathrm{ph}} / J_{\text {sat }}$. Under short-circuit condition, the $P(E, T)$ of INIC, INIC1, INIC2, and INIC3 based OSCs are $94.5 \%, 94.1 \%, 94.2 \%$, and $95.5 \%$, respectively, indicating efficient charge dissociation and collection for all four INIC based OSCs.

We also measured the $J_{\mathrm{SC}}$ versus light density $(P)$ curves to study charge recombination behavior (Figure 2d). The relationship between $J_{\mathrm{SC}}$ and $P$ can be described as $J_{\mathrm{SC}} \propto$ $P^{\alpha}{ }^{59}$ If all the charges are swept out and collected by the electrode before recombination, $\alpha$ should be equal to 1 , while $\alpha$ $<1$ means the existence of charge recombination. The $\alpha$ values of INIC, INIC1, INIC2, and INIC3-based OSCs are 0.983, $0.976,0.981$, and 0.98 , respectively, suggesting negligible bimolecular charge recombination at the short circuit condition.
The hole mobility and electron mobility of the four blended films were measured using the SCLC method (Figure S4). The FTAZ: fluorinated INIC blends exhibit higher electron mobility than the FTAZ: INIC blend (Table S4), resembling the trend in pure INIC series (Table S1). Since hole mobilities of all the blended films are similar $\left(1.8 \times 10^{-4}-3.0 \times 10^{-4} \mathrm{~cm}^{2} \mathrm{~V}^{-1} \mathrm{~s}^{-1}\right)$, the FTAZ/INIC blend shows unbalanced charge transport $\left(\mu_{\mathrm{h}} /\right.$ $\mu_{\mathrm{e}}=13$ ), while the FTAZ/fluorinated INIC blends show more balanced charge transport $\left(\mu_{\mathrm{h}} / \mu_{\mathrm{e}}=1.4-2.4\right)$. Thus, the higher electron mobility and more balanced charge transport in the FTAZ: fluorinated INIC blends are one of the reasons for the higher $J_{\mathrm{SC}}$ and higher FF in these fluorinated INIC-based devices (Table 2).

Film Morphology and Microstructure. To understand the active layer morphology, we first used atomic force microscope (AFM) to obtain the height and phase images of these four active layers (Figure S5). All four active layers (thin films) exhibit smooth surface morphology with a root-meansquare (RMS) roughness of $0.54-0.9 \mathrm{~nm}$. We next employed grazing-incidence wide-angle and small-angle X-ray scattering (GIWAXS and GISAXS) measurements to probe the bulk morphology of these thin films. ${ }^{60,61}$ Figure 3a shows 2D GIWAXS patterns of FTAZ/INIC, FTAZ/INIC1, FTAZ/ INIC2, and FTAZ/INIC3 thin films. The films of FTAZ/INIC, FTAZ/INIC1, and FTAZ/INIC2 exhibit preferential "face-on" oriented molecular packing with the lamellar peak located at $q_{\mathrm{r}}$ $\approx 0.32 \AA^{-1}$ and the $\pi-\pi$ peak located at $q_{z} \approx 1.7 \AA^{-1}$ (Figure $3 b)$, which agree with the corresponding peak positions of pure FTAZ (Figure S6), indicating that the mixing of FTAZ and INIC/INIC1/INIC2 preserves the favorable "face-on" oriented FTAZ semicrystalline domains. Interestingly, the GIWAXS pattern of FTAZ:INIC3 is dramatically different: the face-on oriented domains present a sharp lamella peak at $q_{\mathrm{r}} \approx 0.29 \AA^{-1}$ and a $\pi-\pi$ peak at $q_{z} \approx 1.84 \AA^{-1}$, agreeing with the corresponding lattice constants of pure INIC3 (Figure S6). 

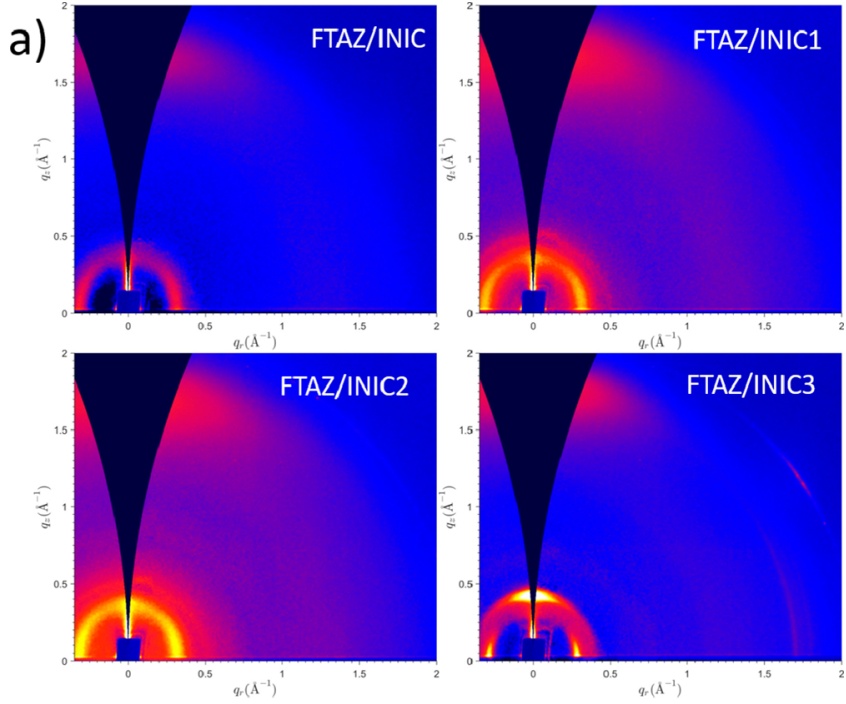

b)
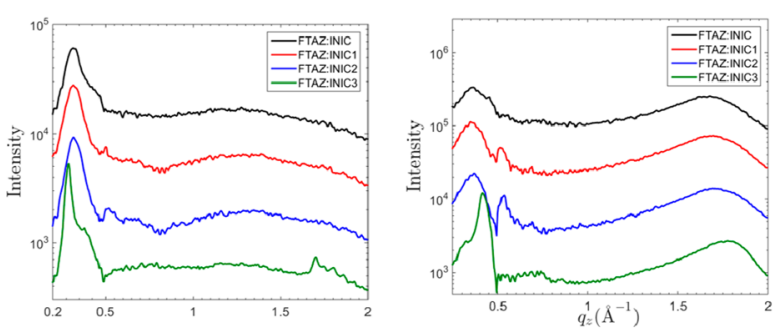

c)

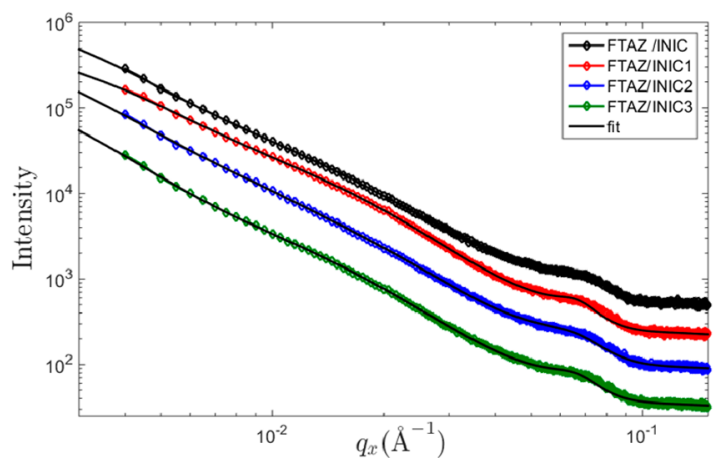

Figure 3. (a) 2D GIWAXS patterns. (b) Corresponding GIWAXS intensity profiles along the in-plane (left) and out-of-plane (right) directions. (c) GISAXS intensity profiles and best fittings along the inplane direction.

Therefore, the lamella peak appearing at $q_{z}=0.42 \AA^{-1}$, clearly visible in the out-of-plane direction (Figure $3 b$, right), should be assigned to "edge-on" oriented FTAZ domains. Notice that the lattice constant of FTAZ shrinks a lot $(d=2 \pi / q=15.0 \AA)$ compared with that of other films $(d=19.6 \AA)$, indicating that the cocrystallization of FTAZ and INIC3 leads to a tighter packing of FTAZ. Thus, FTAZ/INIC3 blend films not only exhibit highest crystallinity compared with other three counterparts, but also maintain both FTAZ and INIC3 semicrystalline packings. Although FTAZ domains reorient into relatively unfavorable "edge-on" orientation, INIC3 domains remain in the favorable "face-on" orientation. This is consistent with the highest electron mobility and more balanced electron and hole mobility observed in the FTAZ/ INIC3 blend film.

Figures $3 c$ and S7 present 2D GISAXS patterns, GISAXS intensity profiles and best fittings along the in-plane direction of pure FTAZ, pure acceptors and the FTAZ/acceptor blends. We adopt the Debye-Anderson-Brumberger (DAB) model, a polydispersed hard sphere model and a fractal-like network model $^{61}$ to account for the scattering contribution from intermixing amorphous phases, FTAZ domains and acceptor domains, respectively. The FTAZ domains remain the same for the four blends $(\sim 4.5 \mathrm{~nm})$ and the acceptor domains are 15.6, 14.5, 23.1, and $17.6 \mathrm{~nm}$ for INIC, INIC1, INIC2, and INIC3, respectively. The correlation lengths of the intermixing phase are 32.6, 27.0, 39.0, and $42.0 \mathrm{~nm}$ for FTAZ/INIC, FTAZ/ INIC1, FTAZ/INIC2, and FTAZ/INIC3, respectively. These results suggest that the nanoscale phase separation of all four films is in a reasonable range for efficient exciton dissociation. The stronger crystallinity of INIC3 does not lead to undesirable micron size aggregation as observed in some small molecule acceptors with strong crystallinity. ${ }^{62}$

\section{CONCLUSIONS}

In summary, four new fused-ring electron acceptors (FREAs), INIC, INIC1, INIC2, and INIC3, based on a fused-nonacyclic IBDT core end-capped with nonfluorinated or fluorinated IC were designed and synthesized for application in nonfullerene OSCs. These four molecules have strong absorption in the visible and even near-infrared region with high extinction coefficients of $2.1-2.5 \times 10^{5} \mathrm{M}^{-1} \mathrm{~cm}^{-1}$. Three fluorinated molecules INIC1, INIC2, and INIC3 show red-shifted absorption and lower HOMO/LUMO energy levels relative to the nonfluorinated INIC due to electron-withdrawing property of fluorine. The fluorinated molecules, particularly the difluorinated INIC3, have higher electron mobilities than INIC without fluorine substitution. FTAZ/INIC3 blend films not only exhibit highest crystallinity compared with other three counterparts, but also maintain both FTAZ and INIC3 semicrystalline packings, possibly due to fluorine-induced intermolecular interactions. This is the main reason for the highest electron mobility and more balanced electron and hole mobility observed in the FTAZ/INIC3 blend film. The nanoscale phase separation of all the films is in a reasonable range for efficient exciton dissociation, and the stronger crystallinity of INIC3 does not lead to undesirable micrometer size aggregation. Since the wide-band-gap polymer donor FTAZ and the narrow-band-gap INIC series acceptors exhibit complementary absorption, matched energy levels and matched mobility, the nonfullerene OSCs based on FTAZ/INIC series blends exhibit small energy loss of $0.61-0.63 \mathrm{eV}$, yet efficient charge dissociation and collection, negligible bimolecular charge recombination, and finally high PCEs of 7.7-11.5\%. Fluorination of INIC significantly enhances the PCE from $7.7 \%$ to $>10 \%$, in particular, the OSCs based on difluorinated INIC3 show the best PCE of $11.5 \%$. These results demonstrate the great potential of the new IBDT and fluorinated IC building blocks for constructing high-performance nonfullerene acceptors.

\section{ASSOCIATED CONTENT}

S Supporting Information

The Supporting Information is available free of charge on the ACS Publications website at DOI: 10.1021/jacs.6b12755.

Detailed experimental procedures including synthesis, characterization and device fabrication, and additional characterization data, such as TGA, SCLC, AFM, GIWAXS, and GISAXS (PDF) 


\section{AUTHOR INFORMATION}

\section{Corresponding Author}

*xwzhan@pku.edu.cn

\section{ORCID ${ }^{\oplus}$}

Xiaowei Zhan: 0000-0002-1006-3342

\section{Notes}

The authors declare no competing financial interest.

\section{ACKNOWLEDGMENTS}

X.Z. wish to thank the 973 Program (No. 2013CB834702) and the NSFC (No. 91433114). T.L. and X.L. acknowledge the financial support from RGC of Hong Kong GRF (No. 14303314) and CUHK Direct Grant (No. 4053128). Q.Z., and W.Y. were supported by the Office of Naval Research (No. N000141410221) and NSF (No. DMR-1507249).

\section{REFERENCES}

(1) Cheng, Y. J.; Yang, S. H.; Hsu, C. S. Chem. Rev. 2009, 109, 5868.

(2) Lu, L.; Zheng, T.; Wu, Q.; Schneider, A. M.; Zhao, D.; Yu, L. Chem. Rev. 2015, 115, 12666.

(3) Lin, Y.; Zhan, X. Acc. Chem. Res. 2016, 49, 175.

(4) Chen, C.-C.; Chang, W.-H.; Yoshimura, K.; Ohya, K.; You, J.; Gao, J.; Hong, Z.; Yang, Y. Adv. Mater. 2014, 26, 5670.

(5) Zhou, H.; Zhang, Y.; Mai, C. K.; Collins, S. D.; Bazan, G. C.; Nguyen, T. Q.; Heeger, A. J. Adv. Mater. 2015, 27, 1767.

(6) Zhao, J.; Li, Y.; Yang, G.; Jiang, K.; Lin, H.; Ade, H.; Ma, W.; Yan, H. Nat. Energy 2016, 1, 15027.

(7) Li, M.; Gao, K.; Wan, X.; Zhang, Q.; Kan, B.; Xia, R.; Liu, F.; Yang, X.; Feng, H.; Ni, W.; Wang, Y.; Peng, J.; Zhang, H.; Liang, Z.; Yip, H.-L.; Peng, X.; Cao, Y.; Chen, Y. Nat. Photonics 2016, DOI: $10.1038 /$ nphoton.2016.240.

(8) Zhan, X.; Facchetti, A.; Barlow, S.; Marks, T. J.; Ratner, M. A.; Wasielewski, M. R.; Marder, S. R. Adv. Mater. 2011, 23, 268.

(9) Lin, Y.; Zhan, X. Mater. Horiz. 2014, 1, 470.

(10) Zhong, Y.; Trinh, M. T.; Chen, R.; Purdum, G. E.; Khlyabich, P. P.; Sezen, M.; Oh, S.; Zhu, H.; Fowler, B.; Zhang, B.; Wang, W.; Nam, C. Y.; Sfeir, M. Y.; Black, C. T.; Steigerwald, M. L.; Loo, Y. L.; Ng, F.; Zhu, X. Y.; Nuckolls, C. Nat. Commun. 2015, 6, 8242.

(11) Zhong, Y.; Trinh, M. T.; Chen, R.; Wang, W.; Khlyabich, P. P.; Kumar, B.; Xu, Q.; Nam, C.-Y.; Sfeir, M. Y.; Black, C.; Steigerwald, M. L.; Loo, Y.-L.; Xiao, S.; Ng, F.; Zhu, X. Y.; Nuckolls, C. J. Am. Chem. Soc. 2014, 136, 15215 .

(12) Wu, Q.; Zhao, D.; Schneider, A. M.; Chen, W.; Yu, L. J. Am. Chem. Soc. 2016, 138, 7248.

(13) Meng, D.; Sun, D.; Zhong, C.; Liu, T.; Fan, B.; Huo, L.; Li, Y.; Jiang, W.; Choi, H.; Kim, T.; Kim, J. Y.; Sun, Y.; Wang, Z.; Heeger, A. J. J. Am. Chem. Soc. 2016, 138, 375.

(14) Meng, D.; Fu, H.; Xiao, C.; Meng, X.; Winands, T.; Ma, W.; Wei, W.; Fan, B.; Huo, L.; Doltsinis, N. L.; Li, Y.; Sun, Y.; Wang, Z. J. Am. Chem. Soc. 2016, 138, 10184.

(15) Sun, D.; Meng, D.; Cai, Y.; Fan, B.; Li, Y.; Jiang, W.; Huo, L.; Sun, Y.; Wang, Z. J. Am. Chem. Soc. 2015, 137, 11156.

(16) Lee, J.; Singh, R.; Sin, D. H.; Kim, H. G.; Song, K. C.; Cho, K. Adv. Mater. 2016, 28, 69.

(17) Zhong, H.; Wu, C.-H.; Li, C.-Z.; Carpenter, J.; Chueh, C.-C.; Chen, J.-Y.; Ade, H.; Jen, A. K. Y. Adv. Mater. 2016, 28, 951.

(18) Lin, H.; Chen, S.; Hu, H.; Zhang, L.; Ma, T.; Lai, J. Y.; Li, Z.; Qin, A.; Huang, X.; Tang, B.; Yan, H. Adv. Mater. 2016, 28, 8546.

(19) Liu, Y.; Mu, C.; Jiang, K.; Zhao, J.; Li, Y.; Zhang, L.; Li, Z.; Lai, J. Y.; Hu, H.; Ma, T.; Hu, R.; Yu, D.; Huang, X.; Tang, B. Z.; Yan, H. Adv. Mater. 2015, 27, 1015.

(20) Liu, J.; Chen, S.; Qian, D.; Gautam, B.; Yang, G.; Zhao, J.; Bergqvist, J.; Zhang, F.; Ma, W.; Ade, H.; Inganäs, O.; Gundogdu, K.; Gao, F.; Yan, H. Nat. Energy 2016, 1, 16089.
(21) Zhang, X.; Lu, Z.; Ye, L.; Zhan, C.; Hou, J.; Zhang, S.; Jiang, B.; Zhao, Y.; Huang, J.; Zhang, S.; Liu, Y.; Shi, Q.; Liu, Y.; Yao, J. Adv. Mater. 2013, 25, 5791.

(22) Zhan, X.; Tan, Z. a.; Domercq, B.; An, Z.; Zhang, X.; Barlow, S.; Li, Y.; Zhu, D.; Kippelen, B.; Marder, S. R. J. Am. Chem. Soc. 2007, $129,7246$.

(23) Lin, Y.; Wang, Y.; Wang, J.; Hou, J.; Li, Y.; Zhu, D.; Zhan, X. Adv. Mater. 2014, 26, 5137.

(24) Sharenko, A.; Proctor, C. M.; van der Poll, T. S.; Henson, Z. B.; Nguyen, T.-Q.; Bazan, G. C. Adv. Mater. 2013, 25, 4403.

(25) Shivanna, R.; Shoaee, S.; Dimitrov, S.; Kandappa, S. K.; Rajaram, S.; Durrant, J. R.; Narayan, K. S. Energy Environ. Sci. 2014, 7, 435.

(26) Guo, Y.; Li, Y.; Awartani, O.; Zhao, J.; Han, H.; Ade, H.; Zhao, D.; Yan, H. Adv. Mater. 2016, 28, 8483.

(27) Hartnett, P. E.; Timalsina, A.; Matte, H. S.; Zhou, N.; Guo, X.; Zhao, W.; Facchetti, A.; Chang, R. P.; Hersam, M. C.; Wasielewski, M. R.; Marks, T. J. J. Am. Chem. Soc. 2014, 136, 16345.

(28) Gao, L.; Zhang, Z. G.; Xue, L.; Min, J.; Zhang, J.; Wei, Z.; Li, Y. Adv. Mater. 2016, 28, 1884.

(29) Earmme, T.; Hwang, Y.-J.; Murari, N. M.; Subramaniyan, S.; Jenekhe, S. A. J. Am. Chem. Soc. 2013, 135, 14960.

(30) Li, H.; Hwang, Y.-J.; Courtright, B. A. E.; Eberle, F. N.; Subramaniyan, S.; Jenekhe, S. A. Adv. Mater. 2015, 27, 3266.

(31) Li, H.; Kim, F. S.; Ren, G.; Hollenbeck, E. C.; Subramaniyan, S.; Jenekhe, S. A. Angew. Chem., Int. Ed. 2013, 52, 5513.

(32) Zhou, E.; Cong, J.; Hashimoto, K.; Tajima, K. Adv. Mater. 2013, $25,6991$.

(33) Zhou, Y.; Kurosawa, T.; Ma, W.; Guo, Y.; Fang, L.; Vandewal, K.; Diao, Y.; Wang, C.; Yan, Q.; Reinspach, J.; Mei, J.; Appleton, A. L.; Koleilat, G. I.; Gao, Y.; Mannsfeld, S. C. B.; Salleo, A.; Ade, H.; Zhao, D.; Bao, Z. Adv. Mater. 2014, 26, 3767.

(34) Zhou, Y.; Ding, L.; Shi, K.; Dai, Y. Z.; Ai, N.; Wang, J.; Pei, J. Adv. Mater. 2012, 24, 957.

(35) Dou, C.; Long, X.; Ding, Z.; Xie, Z.; Liu, J.; Wang, L. Angew. Chem., Int. Ed. 2016, 55, 1436.

(36) Lin, Y.; Wang, J.; Zhang, Z.-G.; Bai, H.; Li, Y.; Zhu, D.; Zhan, X. Adv. Mater. 2015, 27, 1170.

(37) Lin, Y.; Zhao, F.; He, Q.; Huo, L.; Wu, Y.; Parker, T. C.; Ma, W.; Sun, Y.; Wang, C.; Zhu, D.; Heeger, A. J.; Marder, S. R.; Zhan, X. J. Am. Chem. Soc. 2016, 138, 4955.

(38) Lin, Y.; He, Q.; Zhao, F.; Huo, L.; Mai, J.; Lu, X.; Su, C. J.; Li, T.; Wang, J.; Zhu, J.; Sun, Y.; Wang, C.; Zhan, X. J. Am. Chem. Soc. 2016, 138, 2973.

(39) Holliday, S.; Ashraf, R. S.; Wadsworth, A.; Baran, D.; Yousaf, S. A.; Nielsen, C. B.; Tan, C. H.; Dimitrov, S. D.; Shang, Z.; Gasparini, N.; Alamoudi, M.; Laquai, F.; Brabec, C. J.; Salleo, A.; Durrant, J. R.; McCulloch, I. Nat. Commun. 2016, 7, 11585.

(40) Liu, W.; Li, S.; Huang, J.; Yang, S.; Chen, J.; Zuo, L.; Shi, M.; Zhan, X.; Li, C.-Z.; Chen, H. Adv. Mater. 2016, $28,9729$.

(41) Bin, H.; Zhang, Z. G.; Gao, L.; Chen, S.; Zhong, L.; Xue, L.; Yang, C.; Li, Y. J. Am. Chem. Soc. 2016, 138, 4657.

(42) Bin, H.; Gao, L.; Zhang, Z.-G.; Yang, Y.; Zhang, Y.; Zhang, C.; Chen, S.; Xue, L.; Yang, C.; Xiao, M.; Li, Y. Nat. Commun. 2016, 7, 13651.

(43) Yang, Y.; Zhang, Z. G.; Bin, H.; Chen, S.; Gao, L.; Xue, L.; Yang, C.; Li, Y. J. Am. Chem. Soc. 2016, 138, 15011.

(44) Baran, D.; Ashraf, R. S.; Hanifi, D. A.; Abdelsamie, M.; Gasparini, N.; Rohr, J. A.; Holliday, S.; Wadsworth, A.; Lockett, S.; Neophytou, M.; Emmott, C. J. M.; Nelson, J.; Brabec, C. J.; Amassian, A.; Salleo, A.; Kirchartz, T.; Durrant, J. R.; McCulloch, I. Nat. Mater. 2016, DOI: $10.1038 /$ nmat4797.

(45) Li, S.; Ye, L.; Zhao, W.; Zhang, S.; Mukherjee, S.; Ade, H.; Hou, J. Adv. Mater. 2016, 28, 9423.

(46) Yao, H.; Chen, Y.; Qin, Y.; Yu, R.; Cui, Y.; Yang, B.; Li, S.; Zhang, K.; Hou, J. Adv. Mater. 2016, 28, 8283.

(47) Li, Z.; Jiang, K.; Yang, G.; Lai, J. Y.; Ma, T.; Zhao, J.; Ma, W.; Yan, H. Nat. Commun. 2016, 7, 13094

(48) Lin, Y.; Zhao, F.; Wu, Y.; Chen, K.; Xia, Y.; Li, G.; Prasad, S. K.; Zhu, J.; Huo, L.; Bin, H.; Zhang, Z. G.; Guo, X.; Zhang, M.; Sun, Y.; 
Gao, F.; Wei, Z.; Ma, W.; Wang, C.; Hodgkiss, J.; Bo, Z.; Inganas, O.; Li, Y.; Zhan, X. Adv. Mater. 2016, DOI: 10.1002/adma.201604155.

(49) Lin, Y.; Zhang, Z.-G.; Bai, H.; Wang, J.; Yao, Y.; Li, Y.; Zhu, D.; Zhan, X. Energy Environ. Sci. 2015, 8, 610.

(50) Wu, Y.; Bai, H.; Wang, Z.; Cheng, P.; Zhu, S.; Wang, Y.; Ma, W.; Zhan, X. Energy Environ. Sci. 2015, 8, 3215.

(51) Cheng, P.; Zhang, M.; Lau, T.; Wu, Y.; Jia, B.; Wang, J.; Yan, C.; Qin, M.; Lu, X.; Zhan, X. Adv. Mater. 2016, DOI: 10.1002/ adma.201605216.

(52) Lei, T.; Xia, X.; Wang, J.-Y.; Liu, C.-J.; Pei, J. J. Am. Chem. Soc. 2014, 136, 2135.

(53) Sakamoto, Y.; Komatsu, S.; Suzuki, T. J. Am. Chem. Soc. 2001, 123, 4643.

(54) Kim, H. G.; Kang, B.; Ko, H.; Lee, J.; Shin, J.; Cho, K. Chem. Mater. 2015, 27, 829.

(55) Price, S. C.; Stuart, A. C.; Yang, L.; Zhou, H.; You, W. J. Am. Chem. Soc. 2011, 133, 4625.

(56) Li, W.; Albrecht, S.; Yang, L.; Roland, S.; Tumbleston, J. R.; McAfee, T.; Yan, L.; Kelly, M. A.; Ade, H.; Neher, D.; You, W. J. Am. Chem. Soc. 2014, 136, 15566.

(57) Veldman, D.; Meskers, S. C. J.; Janssen, R. A. J. Adv. Funct. Mater. 2009, 19, 1939.

(58) Kawashima, K.; Fukuhara, T.; Suda, Y.; Suzuki, Y.; Koganezawa, T.; Yoshida, H.; Ohkita, H.; Osaka, I.; Takimiya, K. J. Am. Chem. Soc. 2016, 138, 10265.

(59) Schilinsky, P.; Waldauf, C.; Brabec, C. J. Appl. Phys. Lett. 2002, 81, 3885.

(60) Lu, X.; Hlaing, H.; Germack, D. S.; Peet, J.; Jo, W. H.; Andrienko, D.; Kremer, K.; Ocko, B. M. Nat. Commun. 2012, 3, 795. (61) Mai, J.; Lau, T.-K.; Li, J.; Peng, S.-H.; Hsu, C.-S.; Jeng, U. S.; Zeng, J.; Zhao, N.; Xiao, X.; Lu, X. Chem. Mater. 2016, 28, 6186.

(62) Shin, W. S.; Jeong, H.-H.; Kim, M.-K.; Jin, S.-H.; Kim, M.-R.; Lee, J.-K.; Lee, J. W.; Gal, Y.-S. J. Mater. Chem. 2006, 16, 384. 